\title{
ALGUNS ASPECTOS DA OBRA DE PIAGET E SUA CONTRIBUIÇÃO PARA O ENSINO DE QUÍMICA
}

\author{
ALGUNOS ASPECTOS DEL TRABAJO DE PIAGET Y SU CONTRIBUCIÓN A LA \\ ENSEÑANZA QUÍMICA
}

\section{ABSTRACT SOME ASPECTS OF THE WORK OF PIAGET AND ITS CONTRIBUTION TO THE STUDY OF CHEMISTRY}

RESUMO: Este artigo apresenta algumas reflexões relativas à obra de Piaget e suas possíveis influências no cotidiano escolar, em especial no ensino de Química. Para isso, utilizamos autores cujos trabalhos usam como referência a obra de Piaget, além do próprio autor. Nossa intenção é auxiliar educadores a estabelecer uma relação entre os estudos desse epistemólogo, principalmente aqueles relacionados à Epistemologia Genética e o ensino de Química e de áreas afins. Procuramos também deixar claro que não se pretende reduzir a obra de Piaget a questões escolares, uma vez que ela se constitui em algo muito mais abrangente, além do fato de que os interesses pedagógicos se traduzem em interesses, a princípio, diferentes daqueles que são foco das pesquisas de Piaget. Nesse contexto parece-nos pertinente estender nossas considerações às possíveis contribuições de Piaget aos procedimentos de ensino e aos conhecimentos que os professores devem construir para atuarmos de maneira mais eficiente no processo de formação de nossos alunos. Notemos que tanto a escola quanto os estudos de Piaget apresentam em comum o interesse no desenvolvimento da criança.

PALAVRAS-CHAVE: Ensino de química. Epistemologia. Compreensão do conhecimento. Piaget.

RESUMEN: Este trabajo presenta algunas reflexiones sobre la obra de Piaget y sus posibles influencias en la vida cotidiana de la escuela, sobre todo en la enseñanza de la química. Para ello, utilizamos los autores cuyas obras usar como referencia la obra de Piaget y el propio autor. Nuestra intención es ayudar a los educadores a establecer una relación entre los estudios que epistemólogo, especialmente las relacionadas con la epistemología genética y la enseñanza de la química y campos relacionados. También tratamos de dejar claro que no es la intención de reducir el trabajo de Piaget a asuntos de la escuela, ya que es algo mucho más amplio, y el hecho de que los intereses educativos se traducen en intereses, en principio, diferentes de las que son el foco de las investigaciones de Piaget. En este contexto, parece conveniente ampliar nuestras consideraciones a las posibles contribuciones de Piaget a los procedimientos de enseñanza y los conocimientos que los profesores deben construir para que

${ }^{1}$ Professora Doutora em Ensino de Ciências e Matemática. Docente do Departamento de Química da Universidade Estadual de Maringá. Maringá. Paraná. E-mail: mari.zorzi@ hotmail.com

${ }^{2}$ Professor Doutor em Físico-Química. Docente da Universidade Estadual de Maringá. Maringá. Paraná. E-mail: osantin@uem.br.

RIAEE - Revista Ibero-Americana de Estudos em Educação, v.12, n.1, p. 190-204, $2017 . \quad$ E-ISSN: 1982-5587

DOI: http://dx.doi.org/10.21723/riaee.v12.n1.8180 
actúe con mayor eficacia en la educación de nuestro proceso de los estudiantes. Tenga en cuenta que tanto la escuela como los estudios de Piaget tienen un interés común en el desarrollo del niño.

PALAVRAS CLAVE: Enseñanza de la química. La epistemología. La comprensión de los conocimientos. Piaget.

ABSTRACT: This article presents some reflections about Piaget's work and his possible influences in school life, particularly on the chemistry teaching. To achive that, we utilize authors whose works use Piaget's task as a reference, beyond the author's tasks themselves. Our intention is to assist educators to establish a relationship between the studies of this epistemologist, especially those related to genetic epistemology, and the chemistry teaching and related areas. We also want to clarify that it is not intended to reduce the Piaget's work to school issues, since it constitutes something much more comprehensive, beyond the fact that pedagogical interests translate into interests, at first, different from those that are the focus on Piaget's research. In this context it seems appropriate to extend our consideration to possible contributions of Piaget to teaching procedures and knowledge that teachers must build for we act more efficiently in the training of our students process. Note that both the school and the Piaget studies have a common interest in the development of the child.

KEYWORDS: Chemistry teaching. Epistemology. Knowledge understanding. Piaget.

\section{Introdução}

Várias preocupações têm rondado as mentes, as pesquisas e as salas de aulas de muitos professores de Química, e entre elas podemos citar: Como proceder para que o Ensino desse componente curricular no Ensino Médio seja mais articulado com os interesses e necessidades práticas dos alunos e da sociedade em que esses estão inseridos? Qual(is) deve(m) ser a(s) forma(s) de apresentar e trabalhar os assuntos com a intenção de possibilitar a construção de conhecimentos químicos e relacioná-los ao meio social das pessoas? E ainda, de que maneira as aulas de Química devem ser conduzidas de modo a proporcionar aos alunos uma aprendizagem real, muito além de simples memorização, compreendendo que esses devem ser agentes na construção de seus conhecimentos? De que maneira os alunos constroem seus conhecimentos? Como os professores podem contribuir de maneira mais eficaz na mediação de questões relativas à construção de conhecimentos por parte dos alunos? Que conhecimentos teóricos podem embasar a ação pedagógica dos docentes? Tais questões têm sido alvo de 
estudos e pesquisas, não apenas de professores da área, mas também de outras áreas do conhecimento.

$\mathrm{Na}$ tentativa de auxiliar nas respostas referentes a essas indagações e a outras relacionadas ao assunto e que podem surgir em nossa prática pedagógica, tentamos buscar sustentação na relação entre o ensino e a epistemologia de Química à luz dos estudos de Piaget e de autores que nele se referenciaram e, em nosso entendimento, o ponto de partida para essa ação deve ser a compreensão das possíveis contribuições do trabalho de Piaget, levando em conta que se constitui em uma obra epistemológica que pode ser relacionada e utilizada nos ambientes de ensino nos mais diversos componentes curriculares, em nosso caso, o ensino de Química, com o devido cuidado de não reduzir, é claro, sua obra a um pensamento unicamente pedagógico, pois, ela se constitui em algo muito maior do que isso, além do fato de que os interesses pedagógicos se traduzem em interesses, a princípio, diferentes daqueles que são foco das pesquisas de Piaget.

Ao nos reportamos às questões de interesse pedagógico no intuito de traçar uma relação entre esse e a obra de Piaget, e compreender melhor como devemos nos posicionar diante do fato de aplicá-la em nosso cotidiano, temos que lembrar algumas questões que interferem no cotidiano de sala de aula.

Assim, pelo menos três fatores devem ser por nós considerados como determinantes do perfil do ensino escolar: o aumento no número de alunos, que não se deve apenas ao aumento da população, mas também a medidas no âmbito social que aumentou a "democratização" da escola, possibilitando o acesso muito mais geral às diversas formas de ensino; o número pequeno de professores suficientemente formados para atender à demanda atual nas escolas; e o conjunto das necessidades da sociedade atual, sobretudo, as necessidades econômicas, técnicas e científicas (PIAGET, 2008). Esses fatores têm a capacidade de intervir de maneira decisiva na escolha dos procedimentos gerais de ensino.

Além disso, devemos ressaltar que esses procedimentos de ensino podem ficar comprometidos, pois, existem muitos problemas no que se refere à insuficiência de conhecimentos pedagógicos e à falta de vínculo desta com o progresso dos estudos pedagógicos. Nesse sentido, o investimento de cada docente no que se refere à sua formação é muito importante, cabendo a eles estudos que ampliem suas possibilidades de compreensão dos mais diversos contextos escolares.

RIAEE - Revista Ibero-Americana de Estudos em Educação, v.12, n.1, p. 190-204, 2017. $\quad$ E-ISSN: 1982-5587 DOI: $\underline{\text { http://dx.doi.org/10.21723/riaee.v12.n1.8180 }}$ 
Partindo desses pressupostos, reforçamos o fato de que, para que os processos de ensino e aprendizagem conduzam a uma construção de conhecimentos consistente e eficaz, é necessário que o professor compreenda como ela se processa (ARANHA, 2006). Além disso, torna-se evidente a atenção dos docentes aos vários rumos a serem tomados no que se refere à educação, considerando as especificidades das mudanças ocorridas em nossa sociedade, precisando-se determinar com a maior rapidez possível as necessidades que emergem na educação nesse sentido, o que não é tão fácil quanto possa parecer.

No entanto, antes de tratarmos do que aqui nos propomos, ou seja, um breve estudo relacionando a Epistemologia Genética tratada por Piaget e o Ensino de Química, cabe alertarmos que esse não transformará o leitor em um especialista nesse assunto. A obra de Piaget, construída ao longo de muitos anos e com ajuda de vários colaboradores, não pode ser reduzida a algumas páginas sem que se perca conteúdo. Sendo assim, o que pretendemos é colocar o professor interessado no assunto frente a conceitos básicos da obra de Piaget, conceitos esses que, durante a formação docente, na maioria das vezes não foram tratados.

Outro ponto a ser destacado e que reforçaremos em outros momentos desse material é que Piaget não dirigiu sua obra ao ambiente escolar. Sua preocupação sempre foi centrada na gênese do conhecimento na criança e no adolescente. Nesse sentido, as escolas construtivistas ou as teorias construtivistas nas quais essas escolas se alicerçam são desenvolvimentos dados a partir da obra Piagetiana.

\section{A Influência dos Estádios de Desenvolvimento}

Existem muitas hipóteses formuladas a respeito das dificuldades apresentadas pelos alunos ao estudarem e tentarem compreender a Química ensinada nas escolas (CARVALHO, 1983). Segundo essas hipóteses, a maneira com a qual ensinamos Química em nossas escolas de Ensino Médio requer dos alunos uma série de operações ao nível operatório formal para que os conceitos sejam compreendidos. No entanto, grande parte dos alunos não está nesse nível de desenvolvimento intelectual, mas antes, permanecem ainda no nível concreto do desenvolvimento intelectual. Assim, torna-se necessário que os professores entendam o que são esses dois níveis de desenvolvimento.

RIAEE - Revista Ibero-Americana de Estudos em Educação, v.12, n.1, p. 190-204, 2017. $\quad$ E-ISSN: 1982-5587 
O primeiro deles é o estádio operatório concreto, que acontece aproximadamente entre sete (7) e onze (11) anos de idade. Nele ocorre a construção da capacidade de reversibilidade do pensamento. É um período em que a criança desenvolve noções de conservação de número, substância, volume, peso, conceito de número, consegue ordenar elementos por tamanho, organizando o mundo de forma lógica, e são construídas operações lógicas de classificação e de seriação. A criança torna-se capaz de realizar ações mentais, embora limitadas pelo mundo real. Ela já consegue compreender regras e ser fiel a elas, mas não possuem a capacidade de discutir diferentes pontos de vista para chegar a uma conclusão comum. Ocorrem operações sobre os objetos concretos e não sobre hipóteses expressadas verbalmente (CARVALHO, 1983; BESSA, 2008; GOMES \& BELLINI, 2009; PÁDUA, 2009).

O estádio operatório formal, que acontece dos 11 anos em diante, corresponde ao nível do pensamento hipotético dedutivo ou lógico-matemático. $\mathrm{O}$ indivíduo chega ao mundo das operações formais. Esse estádio é considerado o ápice do desenvolvimento da inteligência. Não existe mais a limitação da representação imediata nem apenas as relações previamente existentes. A criança é capaz de pensar em todas as relações possíveis logicamente aplicando o raciocínio lógico aos problemas. A principal característica dessa fase consiste em poder realizar operações sobre hipóteses e não somente sobre objetos, ou seja, ele está apto a calcular uma probabilidade. A partir desse estádio a linguagem se dá ao nível de discussões para chegar a uma conclusão. Também nesse estádio são estabelecidas relações de cooperação e de reciprocidade e a representação permite a abstração total (CARVALHO, 1983; BESSA, 2008; GOMES \& BELLINI, 2009; PÁDUA, 2009).

Conforme Becker (2009), um estudioso de Piaget, não há adolescência sem que se passe do estádio concreto para o operatório formal. Ele ainda difere o termo adolescência, que para Piaget se dá com o ingresso da criança na sociedade dos adultos e isso apresenta variações dependendo das diferentes sociedades e ambientes sociais, do termo puberdade, que se refere à maturação do organismo humano e que se dá em todas as raças e nas diferentes sociedades mais ou menos na mesma idade. A característica marcante da passagem entre os estádios anteriormente citados é o raciocínio hipotético dedutivo, onde o adolescente tem a capacidade de raciocinar sobre proposições.

Devemos salientar que os estádios anteriormente descritos não são os únicos tratados por Piaget, pois ele admite ainda os estádios sensório motor e o pré-operatório. No entanto, os estádios descritos são os que provocam maior interesse para o que estamos tratando nesse RIAEE - Revista Ibero-Americana de Estudos em Educação, v.12, n.1, p. 190-204, $2017 . \quad$ E-ISSN: 1982-5587 DOI: http://dx.doi.org/10.21723/riaee.v12.n1.8180 
artigo. É necessário ressaltar que os quatro estádios (sensório motor, pré-operatório, operatório concreto e operatório formal) representam o desenvolvimento da inteligência, da afetividade e da consciência moral. Independentemente do estádio de desenvolvimentos em que o indivíduo se encontre, a aquisição de conhecimentos ocorre por meio da relação dialética entre sujeito e objeto. É preciso esclarecer que o conhecimento não reside no sujeito, tampouco reside no objeto, mas é decorrente das contínuas interações entre os dois, e que as mudanças mais significativas ocorrem na passagem de um estádio para outro, ao se desfazer o equilíbrio instável e ao buscar-se nova equilibração. A passagem de um estádio para outro é possível pelo mecanismo de organização e adaptação, e essa última, por sua vez, supõe dois processos interligados, a assimilação e a acomodação. Os mecanismos de assimilação e de acomodação são regulados sempre pelo mecanismo de equilibração, num desenvolvimento mútuo e progressivo (ARANHA, 2006; ROSA 2009, ABREU et al, 2010).

Assim, para Piaget, o desenvolvimento é uma questão de equilibração, que acontece por meio de sucessivas situações de equilíbrio - desequilíbrio - reequilíbrio, cuja intenção é ter domínio sobre o objeto do conhecimento sendo que para isso o sujeito executa desde simples ações até operações sobre o objeto. Para compreendermos melhor, a assimilação se caracteriza por ser um processo mental que integra novas informações aos esquemas já existentes. Sendo assim, permite a compreensão de novos objetos, situações e ideias mediante esquemas que o sujeito já possui e, nesse caso, não é necessário modificá-los significativamente.

A acomodação se constitui num processo mental por meio do qual se ajustam os esquemas existentes ou criam-se novos esquemas, e isso ocorre quando as novas informações não podem ser assimiladas. A equilibração se constitui um processo de auto regulação entre os dois processos anteriores e permite a adaptação do sujeito ao meio e uma progressão rumo a um pensamento mais complexo. No entanto, todo o equilíbrio acaba por induzir um novo desequilíbrio e esse movimento entre equilíbrio e desequilíbrio acaba por permitir o desenvolvimento individual do sujeito, chegando a adaptação. Essa acomodação é um processo interno de equilíbrio entre o organismo e o MEIO (ARANHA, 2006; ROSA, 2009, ABREU et al, 2010). Sistematicamente, o equilíbrio entre a assimilação e a acomodação se perturba, o que resulta num estado de desequilíbrio.

A proposta de Piaget é articular, dialeticamente, o princípio da gênese com o da estrutura. Esta perde, assim, seu caráter estático de permanência, para tornar-se estruturante e estruturada. Ou seja, as estruturas vão se modificando 
por um princípio de equilibração e dando origem a novas estruturas que se sucedem (SEMINÉRIO, 1996, p.16).

Portanto, podemos considerar que contribuições de Piaget no aspecto pedagógico têm sido inumeráveis, pois fornece indicações sobre os estádios adequados para serem trabalhados com as crianças os diferentes assuntos, sem o desrespeito às suas reais possibilidades de desenvolvimento intelectual e afetivo. Nessa linha de pensamento, a definição dos períodos de desenvolvimento possibilita o entendimento de que cada um dos indivíduos adquire novos conhecimentos e de que não existe um novo conhecimento sem que o organismo já tenha um conhecimento anterior para poder assimilá-lo e transformá-lo, implicando nos dois polos da atividade inteligente: a assimilação e a acomodação (BESSA, 2008, PÁDUA, 2009).

\section{As ações nas escolas e a obra de Piaget}

No contexto anteriormente descrito parece-nos pertinente estender as nossas considerações às possíveis contribuições de Piaget aos procedimentos de ensino e aos conhecimentos que os professores devem construir para atuarmos de maneira mais eficiente no processo de formação de nossos alunos.

Nessa discussão é importante considerar o fato de que um dos intuitos de Piaget era compreender e descrever modos de pensar das crianças sobre um grande número de questões, analisando o desenvolvimento cognitivo em uma série de estádios. Para isso, ele desenvolveu um método em que a observação, a experimentação e a entrevista com questões abertas que, consideradas simultaneamente, permitiam chegar aos objetivos acima mencionados. Para Piaget, esse trabalho consistia em determinar os níveis sucessivamente necessários para que se passe de uma interação mais simples sobre um dado objeto para uma interação que se traduza em algo mais complexo (CARVALHO, 1983; MACEDO, 1987).

Nesse sentido, Piaget procurava ainda ordenar os diferentes níveis de respostas aos problemas propostos, mostrando que no desenvolvimento da criança existe a necessidade de uma hierarquia (CARVALHO, 1983; MACEDO, 1987). Caracterizou-se então diferentes níveis de um percurso sobre um dado conhecimento, percurso este que parte da noção de algo mais simples que caminha para a noção de algo mais complexo, o que se constitui nos Estádios de Desenvolvimento. Nessa perspectiva, tinha-se conhecimento de como uma criança passa de 
um nível de desenvolvimento a um nível seguinte, bem como a razão dos diferentes níveis na construção de um número muito grande de noções.

Em outras palavras, todo conhecimento contém um aspecto de elaboração nova, e o grande problema da epistemologia consiste em conciliar essa criação de novidades com o fato duplo de que, no terreno formal, elas se fazem acompanhar de necessidades imediatamente elaboradas, e de que, no plano do real, permitem (e são de fato as únicas a permitir) a conquista da objetividade (PIAGET, 2007, p.1).

A epistemologia genética objetiva determinar, distinguir e diferenciar a gênese dos diversos conhecimentos, partindo para isso de suas formas mais elementares e, a partir disso, acompanhar e observar seu desenvolvimento para obter respostas para questões relativas ao caminho dos processos cognitivos (PIAGET, 2007).

Segundo Macedo (1987), devemos ter em mente que, com suas pesquisas, o interesse de Piaget era com a compreensão do conhecimento e de sua construção, resultado de interações entre a criança e os objetos, então, fundamentalmente de natureza epistemológica e não psicológica ou pedagógica, num movimento para recuperar a gênese das noções e as diferentes maneiras de estruturação cognitiva, indo de um nível mais simples a um nível mais complexo.

Ainda segundo Macedo (1987), pode-se verificar a diferença existente entre os interesses mencionados e atribuídos a Piaget e ao que se pretende em nível de Educação, uma vez que essa se preocupa e se ocupa mais com a promoção do desenvolvimento e está interessada na aprendizagem da criança como sendo o resultado de sua ação sobre ela. Enquanto isso, o interesse de Piaget está centrado na descrição dos níveis de desenvolvimento de uma noção na criança, bem como em recuperar os processos que estão presentes na construção do conhecimento, visando responder a questões não só de como os indivíduos sozinhos ou em conjunto constroem conhecimento, mas também por quais processos e por que etapas fazem isso (ABREU et al, 2010).

Notemos que tanto a escola quanto os estudos de Piaget apresentam em comum o interesse no desenvolvimento da criança. No entanto, eles seguem por caminhos e orientações diferentes. Enquanto a escola apresenta uma intenção prática, interessando-se pela aprendizagem da criança ao retirá-la de seu estado atual para um estado considerado melhor, Piaget apresenta um interesse epistemológico que se traduz na compreensão e descrição detalhada dos níveis de desenvolvimento, daí o nome Epistemologia Genética, escolhido pelo autor para parte de sua obra. Nesse sentido, Piaget destaca que a Epistemologia Genética tem 
entre seus objetivos explicar a continuidade existente entre os processos biológicos e cognitivos sem tentar fazer com que esses processos cognitivos se reduzam a processos biológicos mas, antes, dando a cada um sua real importância.

Macedo (1987) deixa claro que essa linha de pensamento tem como um de seus objetivos esclarecer que a aplicação pedagógica da teoria de Piaget requer cuidados muitas vezes ignorados e que essa aplicação não pode ser simplista e direta, implicando ainda em uma mudança de referencial. O autor ainda comenta que, ao se trabalhar com a obra de Piaget na escola numa aplicação dita pedagógica, deve-se ter cuidado para que os pressupostos fundamentais de sua obra sejam preservados e bem aplicados para que não se tenha apenas a ilusão de que a prática pedagógica está baseada em Piaget, enquanto na realidade, não está.

Ao professor, que parte de uma ciência inteiramente construída e que, a princípio acredita conhecer, cabe a reflexão sobre a sua prática, cabe ainda conhecer ou ampliar o conhecimento referente à teoria piagetiana para que consiga compreender a sala de aula e o problema da construção de conhecimentos sob um ponto de vista mais amplo e não restrito ao conteúdo, mas, sim, com um foco no processo de desenvolvimento intelectual do aluno de maneira que também o saber o que ensinar, o como ensinar e o quando ensinar possa ser mais bem compreendido (CARVALHO, 1983).

Cabe ressaltar aqui algumas particularidades que envolvem a epistemologia das ciências para que possamos traçar alguns paralelos com a Química, especificamente. Segundo Bellini:

As características do conhecimento biológico fizeram-no muito diferente do físico e do matemático; as ciências biológicas não podem construir seu campo de conhecimento sem a primazia de seus objetos. Já para a elaboração dos conhecimentos matemáticos, podemos dizer que a primazia é do sujeito. $\mathrm{Na}$ física, sujeito e objeto se equivalem. Por isso, a comparação da atividade mental do sujeito cognoscente, sob seus diversos aspectos, diante desses conhecimentos, é uma questão relevante para a reflexão epistemológica tanto no âmbito científico como no escolar (BELLINI, 2006, p.32).

Guiados por esse raciocínio, podemos dizer que o ensino da Matemática recorre, sobretudo, a atividades dedutivas, não sendo necessário recorrer à observação e à experimentação. Nele, o papel do objeto é ínfimo e o do sujeito é grande, sendo a Matemática um produto da atividade do sujeito. O ensino da Física caracteriza-se por um equilíbrio entre o papel da experimentação e da dedução, não podendo esquecer que a dedução na Física é um processo da Matemática e que o conhecimento físico marca a interdependência entre o sujeito e o objeto. No ensino de Biologia a dimensão atribuída à dedução é menor que na Física e bem RIAEE - Revista Ibero-Americana de Estudos em Educação, v.12, n.1, p. 190-204, $2017 . \quad$ E-ISSN: 1982-5587 DOI: http://dx.doi.org/10.21723/riaee.v12.n1.8180 
menor que na Matemática, portanto, a experimentação se destaca, existindo um papel muito relevante em relação ao objeto (BELLINI, 2006).

Nessa perspectiva, acreditamos que o ensino de Química apresenta uma dimensão epistemológica que hora se aproxima da epistemologia da Biologia (ao valorizar a experimentação e o objeto) e hora se aproxima da epistemologia da Física (ao equilibrar o papel da experimentação e da dedução e considerar a interdependência entre sujeito e objeto). Também acreditamos que a experimentação e a formulação matemática estão constantemente de mãos dadas, de maneira a complementarem-se em muitos momentos e, além disso, o objeto do conhecimento da Química, que em nosso entendimento é a matéria, suas estruturas e suas transformações, acaba sendo a princípio resultado de uma reflexão teórica.

Ao nos referirmos especificamente ao ensino de Química, podemos dizer que é muito comum a utilização de modelos de ensino cuja função é a de facilitar o processo de aprendizado dessa ciência e de auxiliar os estudantes a compreenderem modelos consensuais. No entanto, a elaboração de tais modelos não é algo tão simples como a primeira vista possa parecer. Ele deve ser idealizado de tal forma que, durante o processo de ensino e de aprendizagem, o professor consiga trabalhar de maneira a preservar a estrutura e as características do modelo consensual sem apenas simplificá-lo, e ainda ser capaz de considerar os conhecimentos prévios dos alunos, com a intenção de que esses tenham a capacidade de construir conhecimentos e compreender os conceitos. Os modelos então são apresentados na forma de objetos concretos, analogias, desenhos e simulações das mais diversas (MILAGRES \& JUSTI, 2001).

Portanto, podemos dizer que a Matemática, a Física, a Biologia e a Química atuam de maneiras diferentes e em campos diferentes, abordando objetos também diferentes.

Com essa base de informações, voltemos nosso olhar novamente para a escola. Percebemos que, ao procurarmos nas obras de Piaget uma aplicação direta de suas teorias no trabalho escolar, muitas vezes podemos nos decepcionar. Provavelmente é isso que deixa a muitos intrigados e o que leva a pensar que sua obra é difícil e complexa, pois ela se traduz em questões teóricas que escapam muitas vezes à prática pedagógica. Isso não significa, porém, que não sejam encontrados em sua obra subsídios considerados fundamentais para o trato pedagógico. Portanto, além de investir tempo com estudos da obra de Piaget, existe a necessidade de uma constante pesquisa que esteja voltada às possibilidades de aplicação desses estudos, bem como a intencionalidade na articulação desses dois caminhos. Nesse sentido, os estudos teóricos são base para a aplicação prática, pois, a rigor, não existem propostas 
pedagógicas que mostrem como devem ser utilizadas as ideias de Piaget, e, no entanto, essas ideias podem servir de diretrizes para metodologias a serem trabalhadas no ambiente escolar, visando o processo de ensino e de aprendizagem.

Para Macedo (1987), o modo mais interessante de se aplicar a obra de Piaget na prática escolar é o de nos esforçarmos de maneira incessante para que teoria e prática andem juntas, em um movimento constante e coordenado, com as devidas diferenciações e integrações. Nesse sentido, além de ser necessário o conhecimento e o constante estudo da obra de Piaget, é necessária uma constante pesquisa e revisão voltadas para as possibilidades de aplicação, bem como uma análise sistemática do modo como a aplicação está sendo realizada.

Carvalho (1983) comenta que, normalmente, os alunos se referem à Química como uma disciplina muito difícil e muitas vezes até incompreensível, e o fato de os alunos encontrarem dificuldades é muito mais evidente do que o conhecimento das causas que provocam essas dificuldades. A autora, referenciando-se em vários outros autores como Herron, Good, Kromhout, Mellon, Goodstein e Howe, levanta a hipótese de que as dificuldades encontradas pelos alunos quando se refere ao ensino de Química se dá ao fato de que eles ainda não estão no nível de desenvolvimento intelectual que Piaget se referente com estádio formal, mas sim no nível concreto do desenvolvimento intelectual.

Nessa linha de pensamento, Ferracioli (1999) afirma que desde o momento do nascimento até a idade adulta se dá o desenvolvimento mental de um indivíduo. Esse é um processo contínuo de construção de estruturas variáveis que ocorre juntamente com características constantes e comuns a todas as idades. Isso tudo reflete o grau de desenvolvimento intelectual do indivíduo. E esse desenvolvimento não pode ser confundido com a aprendizagem, que, segundo Piaget,

O desenvolvimento é um processo que diz respeito à totalidade das estruturas de conhecimento. Aprendizagem apresenta o caso oposto. Em geral, a aprendizagem é provocada por situações - provocada por psicólogos experimentais; ou por professores em relação a um tópico específico; ou por uma situação extrema. Em geral, é provocada e não espontânea. Além disso, é um processo limitado - limitado a um problema único ou a uma estrutura única. Assim, eu penso que desenvolvimento explica aprendizagem, e essa opinião é contrária à opinião amplamente difundida de que o desenvolvimento é uma soma de experiências discretas de aprendizagem (PIAGET, 1964, p.176).

RIAEE - Revista Ibero-Americana de Estudos em Educação, v.12, n.1, p. 190-204, 2017.

E-ISSN: 1982-5587

DOI: http://dx.doi.org/10.21723/riaee.v12.n1.8180 
Sendo assim, a escola e, mais precisamente a educação, deve possibilitar à criança uma construção de conhecimentos que seja ampla e dinâmica em todos os momentos do seu desenvolvimento cognitivo.

No que diz respeito às ações pedagógicas, Piaget considera o método tradicional superado, pois o mesmo concebe o aluno como um ser apático e vago que fica à espera de conhecimentos transmitidos. Entre suas ideias existem reflexões sobre um ensino que seja formador de um raciocínio lógico que leve à compreensão e à interpretação em detrimento da memorização. Diante do exposto, parece-nos claro que não se pode mais pensar o ensino de Química ou de qualquer outro componente curricular que seja pautado na repetição e verbalização de conteúdos.

Esse fato nos remete às questões do construtivismo pensado por Piaget em sua obra Epistemologia Genética. Conforme Becker (2009), o termo construtivismo e mais ainda sua aplicação, significa que nada a rigor pode ser considerado pronto e acabado, incluindo nesse sentido o próprio conhecimento.

Construtivismo é, portanto, uma ideia, melhor, uma teoria, um modo de ser do conhecimento ou um movimento do pensamento que emerge do avanço das ciências e da filosofia dos últimos séculos. Uma teoria que nos permite interpretar o mundo em que vivemos. No caso de Piaget, o mundo do conhecimento: sua gênese e seu desenvolvimento. Construtivismo não é uma prática ou um método; não é uma técnica de ensino nem uma forma de aprendizagem; não é um projeto escolar; é sim, uma teoria que permite (re)interpretar todas essas coisas, jogando-nos para dentro do movimento da História - as Humanidade e do Universo. (BECKER, 2009, p.2).

Para Becker (2009), o que foi dito anteriormente nos remete ao sentido do Construtivismo na Epistemologia Genética piagetiana. Quando nos reportamos ao Construtivismo na educação devemos encará-lo como uma forma teórica ampla e que reúna as mais diversas tendências atuais do pensamento e das ações pedagógicas. Nessa perspectiva, nos referimos às tendências que se sintam incomodadas com essa atual forma de transmissão dos conteúdos que se incomodem com uma escola "Que consiste em fazer repetir, recitar, aprender, ensinar o que já está pronto, em vez de fazer agir, operar, criar, construir a partir da realidade vivida por alunos e professores" (BECKER, 2009, p.3).

Segundo Macedo (2002), atuar de maneira construtivista significa ter uma prática pedagógica com base não apenas na transmissão (e, nesse caso, ele não ignora seu valor em alguns momentos do processo educativo na escola), mas implica também em tratar a prática pedagógica como uma investigação, como uma experimentação.

RIAEE - Revista Ibero-Americana de Estudos em Educação, v.12, n.1, p. 190-204, $2017 . \quad$ E-ISSN: 1982-5587 DOI: http://dx.doi.org/10.21723/riaee.v12.n1.8180 
Construir conhecimento implica em deduzi-lo a partir de outro já sabido ou dado, ainda que parcialmente, Essa parcialidade corresponde ao limite das relações sujeito/objeto. Mas, uma coisa é uma dedução pensada em um contexto de pesquisa, de diálogo, de experimentação, de busca de argumentação; outra ela é tida como pressuposto (MACEDO, 2002, p. 36).

Portanto, muito mais do que saber bem os conteúdos a serem tratados para ter a possibilidade de transmitir ou avaliar corretamente, trata-se mais de saber para que se possibilite ao aluno participar de uma discussão para compreender e localizar na história da ciência o ponto correspondente ao pensamento dela e para, a partir daí, formular hipóteses, sintetizando quando for necessário. Por isso, o professor deve adotar uma nova postura (Macedo, 2002). Com isso, os próprios materiais de ensino devem ser utilizados nessa perspectiva, as aulas devem ser de tal maneira que o aluno trabalhe, aja, se envolva, faça. As avaliações devem ser pensadas em novas bases, diferentes instrumentos avaliativos devem ser colocados à disposição de uma avaliação realmente pensada como auxiliar do processo de aprendizagem.

Ora, pensando na Epistemologia Genética e relacionando-a com a escola, podemos dizer que ela pode dar suporte para combater o imediatismo do fazer na escola, concebendo o espaço escolar como um espaço histórico e científico onde o sujeito é valorizado à medida que o objeto também o é.

Muito embora Piaget não fosse um pedagogo e sim epistemólogo, não podemos negar o fato de que sua obra tem exercido significativa influência nas questões pedagógicas há bastante tempo, pois ele investigou o desenvolvimento cognitivo da criança desde o seu nascimento até a adolescência.

\section{Considerações Finais}

Entre os diferentes aspectos de nosso trabalho, acreditamos que seja conveniente ressaltar alguns pontos. A princípio, devemos ter em conta que a obra de Piaget não propõe um método de ensino aplicável na escola, um método que seja claro, que determine os caminhos pelos quais os professores devem seguir rumo ao êxito na educação e formação de seus alunos, mas, sim, se caracteriza por ser uma obra que apresenta uma teoria do conhecimento cujos resultados podem ser, e o são, usados por muitos psicólogos, pedagogos e educadores de uma 
maneira geral. Esse fato nos dá a certeza de que as obras epistemológicas são sujeitas a várias interpretações e apresentam, portanto, resultados diferentes, pois acabam provocando o surgimento de propostas didáticas muito diversas.

É necessário o estudo teórico da obra de Piaget para que se possa transpor as barreiras existentes para uma aplicação prática no ambiente escolar, pois deve ficar claro que Piaget jamais formulou uma teoria da aprendizagem ou uma teoria aplicável diretamente ao ambiente escolar. Seu objetivo não era esse, mas o de compreender como o conhecimento é construído, razão pela qual ele é considerado um epistemólogo. Portanto, sua pesquisa deve servir como um fio condutor para o estudo por parte dos professores interessados em conhecer, discutir, utilizar e repensar sua teoria.

Além disso, foi nosso objetivo tratar um pouco sobre a obra de Piaget, tentando compreender o que é o desenvolvimento intelectual, como se dá a construção de conhecimentos pelo sujeito, e ainda qual a importância do conhecimento da obra de Piaget para o processo de ensino e de aprendizagem, que pode ocorrer pela articulação dos aspectos mencionados e, nesse sentido, estabelecer diretrizes que auxiliem o cotidiano escolar baseado no referencial piagetiano, o que acreditamos ser de interesse dos professores, para que tenham a capacidade de desempenhar suas ações pedagógicas com mais propriedade.

Por fim, partindo-se do pressuposto de que as decisões tomadas em relação às ações pedagógicas em sala de aula pelos professores são em grande parte determinadas pela sua história de vida e pelas suas crenças epistemológicas, acreditamos que a compreensão da obra de Piaget se faz imprescindível.

\section{Referências}

ABREU, L. C. de et al. A Epistemologia Genética de Piaget e o Construtivismo. Revista Brasileira de Crescimento e Desenvolvimento Humano. V.20, n.2, p.361-366, ago, 2010. ARANHA, M. L. de A.; História da Educação e da Pedagogia: Geral e Brasil. 3 ed. São Paulo: Ed moderna, 2006.

BECKER, Fernando. O que é construtivismo? Desenvolvimento e Aprendizagem sob o Enfoque da Psicologia II, UFRGS-PEAD, 2009. Disponível em: <http://livrosdamara.pbworks.com/f/oquee_construtivismo.pdf >. Acesso em: 28 de março de 2014. 
BELLINI, M. Epistemologia da Biologia: para se pensar a iniciação ao ensino das Ciências Biológicas. Revista Brasileira de Estudos Pedagógicos. v.88, n.218, p.30-47, jan/abr 2006. BESSA, V da H. Teorias da Aprendizagem. IESDE Brasil S.A. Curitiba, 2008.

CARVAlHO, A. M. P. de; Piaget e o Ensino de Ciências. Revista da Faculdade de Educação. v.9, n.1, p.55-77, 1983.

FERRACIOLI, L. Aprendizagem, desenvolvimento e conhecimento na obra de Piaget: uma análise do processo de ensino-aprendizagem em Ciências. Revista Brasileira de Estudos Pedagógicos. v.80, n.194, p. 5-18. Jan/abr. 1999.

GOMES, L. C; BELLINI, L. M. Uma visão sobre aspectos fundamentais da teoria de Piaget: possíveis implicações para o ensino de Física. Revista Brasileira de Ensino de Física. v.31, n.2, p. 2301-1-2301-10. jun. 2009.

MACEDO, L. Para uma aplicação Pedagógica da Obra de Piaget: Algumas Considerações. Caderno de Pesquisa. n.61, p. 68-71, São Paulo, maio, 1987.

MACEDO, L. Ensaios construtivistas. São Paulo: Casa do Psicólogo, 2002.

MILAGRES, V. S. O. e JUSTI, R. S.; Modelos de Ensino de Equilíbrio Químico: Algumas considerações sobre o que tem sido apresentado em Livros Didáticos do Ensino Médio.

Química Nova na Escola. n.13, p.41-46, maio, 2001

PÁDUA. G. L. D de. A Epistemologia Genética de Jean Piaget. Revista FACEVV. n.2, p. 22-35. Vila Velha/ES, 2009.

PIAGET, J. Seis estudos de Psicologia. Rio de Janeiro: Forence, 1967. Título original: Six études de psychologie. 1964.

PIAGET, J. Epistemologia Genética. 3 ed. São Paulo: ed. Martins Fontes, 2007.

PIAGET, J. Psicologia e Pedagogia. 9.ed. Rio de Janeiro: ed. Forence Universitária, 2008.

ROSA, Roseli Scuinsani da. Piaget e a Matemática. In: I Simpósio Nacional de Ensino de Ciências e Tecnologia. 2009, Curitiba. Anais... Curitiba: UTFPR, 2009.p.801-807.

SEMINÉRIO, Franco L. P. Piaget: O Construtivismo na Psicologia e na Educação. Rio de Janeiro: Imago Editora LTDA, 1996.

\section{Como referenciar este artigo:}

SÁ, Marilde Beatriz Zorzi; SANTIN FILHO, Ourides. Alguns Aspectos da Obra de Piaget e sua Contribuição para o Ensino de Química. Revista IberoAmericana de Estudos em Educação, Araraquara, v.12, n.1, p. 190-204, 2017. Disponível em: E-ISSN: 19825587.

Submetido em: out/2015

Aprovação final em: fev/2017

RIAEE - Revista Ibero-Americana de Estudos em Educação, v.12, n.1, p. 190-204, 2017. $\quad$ E-ISSN: 1982-5587

DOI: http://dx.doi.org/10.21723/riaee.v12.n1.8180 